\title{
Deep drawing of a stellar shape using finite element simulation and experimental

\author{
Waleed Khalid Jawad ${ }^{1}$ and Ali T. Ikal ${ }^{2}$
}

${ }^{1}$ Production and Metallurgy Engineering Department, University of Technology/Baghdad....... Al-Sinaa' Street, 10066, Baghdad, Iraq

${ }^{2}$ Production and Metallurgy Engineering Department, University of Technology/Baghdad........ Al-Sinaa' Street, 10066, Baghdad, Iraq

\begin{abstract}
The process of deep drawing of complex shapes is a difficult process compared to the process of drawing simple shapes such as cylindrical, square and rectangle because of the complex shape is subjected to the higher stresses concentration compared to simple shapes. This work aims to study the effect of the wall corner radius of punch and radial clearance on deep drawing operation using the experimental work and numerical simulation. In this work, an analysis of the deep drawing process is performed for process design of stellar cup drawing. A deep drawing die was designed and manufacturing to perform the experimental procedure required to produce a stellar cup with inner dimensions (major axis equal to $43.7 \mathrm{~mm}$ and minor axis equal to $36.64 \mathrm{~mm}$ ) formed from a circular flat sheet ( $80 \mathrm{~mm}$ diameter) comprised of low carbon steel of $(0.08 \%)$ carbon content, without any intermediate annealing. A commercially finite element program code (ANSYS 18.0) is utilized to simulate the stellar deep drawing operation. From the comparison between the results, it has been found that the thinning at cup corner increases by decreasing the wall corner radius of the punch and the maximum thinning with the wall corner radius of the punch equal to $\left(R_{c p}=2 \mathrm{~mm}\right)$ at the corner of the minor axis of completely drawn cup.
\end{abstract}

Keywords: deep drawing of the stellar cup.

\section{Introduction}

Deep drawing is one of the extensively used sheet metal forming processes in the industries to have mass production of cup shaped components in a very short time. In this metalworking operation, a blank is drawn into a die using a special punch to produce a cup shape product. Deep drawing products in modern industries usually have a complicated shape, so these have to undergo several successive operations to obtain a final desired shape [1].

Many studies have addressed the deep drawing process for symmetric and axisymmetric shapes and focused on some variables to obtain the final product without defects such as thinning and wrinkling in the drawing operation. Han and Huh,[2] carried out the deep drawing of a square shape from a circular blank to study the influence of thickness on the distribution of strain and punch load and the influence of size on an initial wrinkling happening without a blank holder. It has been found that two wrinkles are shaped at a flank of a blank, when the size of the blank is the large one wrinkle is formed as buckling.

Anwekar and Jain, [3] proposed a numerical procedure for the design of conical cup in deep drawing operation using numerical simulation. Also the effect of blank size, drawing load, blank holder force and punch/ die design on the distribution of stress were investigated. It was found that it is possible to perform a successful conical cup.

Reddy, et al, [4], conducted an experimental study on single stage deep drawing operation of cylindrical shape for valuation of radial strain, hoop strain, and thickness different in aluminum alloyAA6061. It has been noted that deeper shapes were performed by choosing the optimum design variables and the results are in good agreement with simulation results.

Alin, et al, [5] studied the effect of die corner radius, punch corner radius and blank holder force on wrinkling phenomenon in deep drawing cylindrical parts. The results show that the die corner radius has a major effect on wrinkling phenomenon, but we must use a value of 0.01 coefficient of friction, which leads to blank holder force less effect in deep drawing operation.

Sener and Kurtaran, [6] investigated deep drawing operation of a rectangular cup using numerically and experimentally. The distribution of thickness predicted from the numerical analysis was compared with experimental work measurements. It was noted that maximum thinning occurs at the punch profile radius.

Pranavi and Ramulu, [7] investigated the drawability of a square cup of Aluminum alloy plates using a deep drawing process. The effects of die profile radius, lubricating conditions, punch profile radius, and blank holding pressure on drawing load, distribution of thickness and cup height observed.

Younis, et al, [8] evaluated the forming of a square cup in deep drawing operation also the effect of die corner radius, blank size and radial clearance between the punch and die on deep drawing were estimated. It is observed the 
more thinning occurs in the profile cup due to more stretching appear in this zone.

The research aims to design and manufacture die to produce stellar shape from a circular flat sheet also the effect of wall corner radius of punch and radial clearance was investigated

\section{Numerical Simulation}

Commercial finite element analysis code ANSYS18.0 structural was used to model and simulate the deep drawing operation, in which the nonlinear issues are solved by using "implicit method "Newton-Raphson. The stellar cup with inner dimensions (major axis $41.5 \mathrm{~mm}$ and minor axis 34.96) and length (30mm). The blank from which it is formed has a diameter of $(80 \mathrm{~mm}),(0.7 \mathrm{~mm})$ thickness and is comprised of low carbon steel of carbon. Mechanical properties of the low carbon steel used in the analysis are listed in the table (1). The 3-D 8-node structural solid element of SOLID185 was used for blank sheet. The contact interface between the tool and blank sheet can be simulated automatically, where target element TARGE170 is utilized to represent the rigid tools (punch, die and blank

holder), while contact element CONTA174 is used to represent the deformable blank sheet. Fig (1) shows the element contact between the die (punch, die, and plank holder) and blank sheet used in the analysis. The coefficient of friction between tool material and blank material interface $(\mu=0.1)$. The blank holding force was ranging from $(10-12 \mathrm{KN})$ during the full stroke of operation. Three types of stellar punches equal to $\left(R_{c p}=\right.$ 2, 4, $6 \mathrm{~mm}$ ) were used to studied the influence of punch geometric deep drawing operation. Four types of clearance $\left(1.1 \mathrm{t}_{\mathrm{o}}, 1.15 \mathrm{t}_{\mathrm{o}}, 1.2 \mathrm{t}_{\mathrm{o}}\right.$, and $\left.1.25 \mathrm{t}_{\mathrm{o}}\right)$ are used were used to study the influence of radial clearance on thickness distribution. The successive steps of the deep drawing for effective stress are shown in fig (2).

Table 1 Mechanical properties of the low carbon steel.

\begin{tabular}{|c|c|}
\hline Property & Value \\
\hline Yield stress $(\mathrm{MPa})$ & 223 \\
\hline Young modulus $(\mathrm{GPa})$ & 200 \\
\hline Tangent modulus $(\mathrm{GPa})$ & 0.5 \\
\hline Mass density $\left(\mathrm{gm} / \mathrm{cm}^{\wedge} 3\right)$ & 7.8 \\
\hline Poisons ratio & 0.5 \\
\hline
\end{tabular}

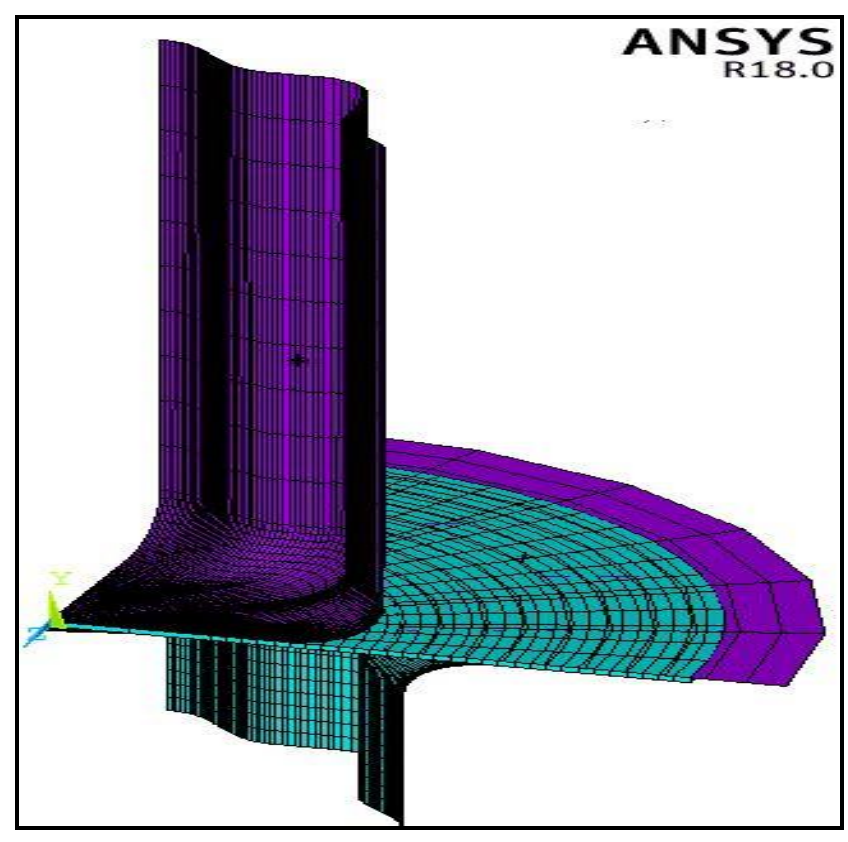

Fig. 1 Photograph shows the element contact between the die (punch, die, and plank holder) and blank sheet.

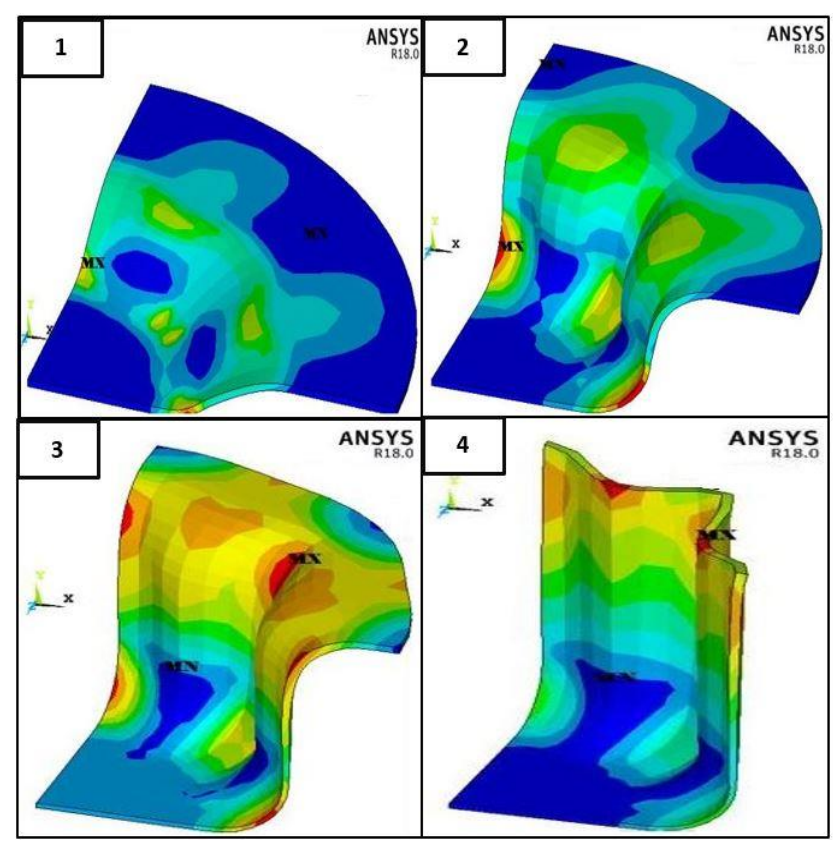

Fig. 2 Photograph shows the successive steps of the deep drawing for effective stress.

\section{Experimental procedure}

Experimental tooling was designed and constructed to produce stellar cup, they are made from tool steel which was machined by wire cut machine and polished in order to obtain good surface finish. The experiments were performed using the universal testing machine which has a capacity of $200 \mathrm{KN}$ and cross head speed $(0-500 \mathrm{~mm} / \mathrm{min})$, the tool of the deep drawing process used in this study is shown in fig (3). 
Low carbon steel circular blank sheet from which has $(0.7 \mathrm{~mm})$ thickness and diameter of $(80 \mathrm{~mm}$ was used. The chemical composition of low carbon steel is listed in the table (1). The deep drawing was performed using stellar punch with dimensions equal to (41.5 $\mathrm{mm}$ by34.96 $\mathrm{mm}$ ) manor and minor axis respectively and die diminutions equal to $(43.7 \mathrm{~mm}$ by $36.64 \mathrm{~mm})$ inner manor and inner minor axis respectively and dies clearance equal to (20\% sheet thickness) is chosen as shown in fig (4) .

Deep drawing tests include drawing processes to produce stellar cups without flange with inner dimensions equal to (41.5 $\mathrm{mm}$ by34.96 $\mathrm{mm}$ ) major and minor axis respectively and height of $(30 \mathrm{~mm})$ as shown in fig (4). Three types of stellar punches equal to $\left(R_{c p}=2,4,6 \mathrm{~mm}\right)$ and punch profile radius equal to $\left(R_{c p}=6 \mathrm{~mm}\right)$ were used in order to investing the effect of wall corner radius of punch on distribution of stress, strain and thickness across side wall, the major axis corner and the minor axis corner of completely drawn cup and cup height. The wall corner radius of the die and die profile radius $\left(R_{c d}=4 \mathrm{~mm}\right.$ and $R_{d}=6$ ). Also, study the effect of the radial clearance between the punch and die on the distribution of thickness along the side wall, the corner of the major axis and the corner of the minor axis of the stellar cup

In order to study the strain distribution across the side wall, the corner of the major axis and the corner of the minor axis of the drawn part, grid square was printed on the blank with the dimension of $(2 \times 2 \mathrm{~mm})$ using a laser machine as shown in Fig (5-A). When the specimen deforms, the grid squire will deform with the material and will visualize the deformations imposed on the sheet as shown in Fig (5-B). In order to measure the cup wall thickness, the drawn cup is cut into two parts by using a wire cut machine. Thickness micrometer and tool microscope was used to measure the cup wall thickness and change in the grid squire after deformation. Cup thickness and the length of the distorted grid radius were measured. Radial strain and thickness strain distribution was measured.

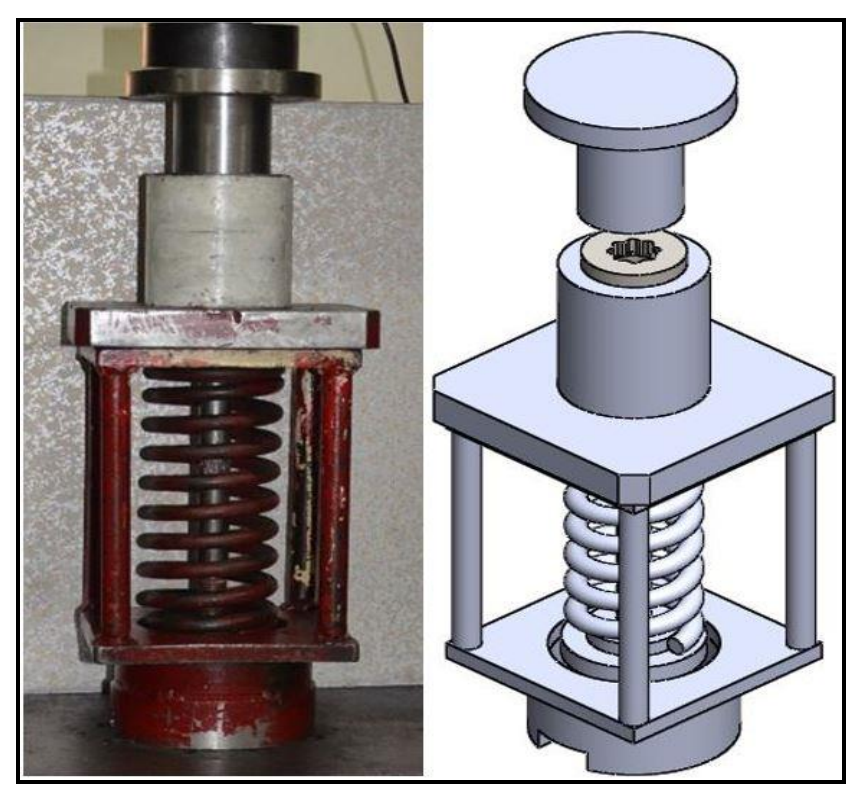

Fig. 3 Photograph shows the tool of the deep drawing process.

Table 2 The chemical composition of low carbon steel

\begin{tabular}{|c|c|c|c|c|}
\hline $\mathrm{C} \%$ & $\mathrm{Si} \%$ & $\mathrm{Mn} \%$ & $\mathrm{p} \%$ & $\mathrm{~S} \%$ \\
\hline 0.08 & 0.02 & 0.169 & 0.016 & 0.006 \\
\hline $\mathrm{S} \%$ & $\mathrm{Cr} \%$ & $\mathrm{Ni} \%$ & $\mathrm{Mo} \%$ & $\mathrm{Cu} \%$ \\
\hline 0.055 & 0.035 & 0.002 & 0.006 & 0.09 \\
\hline
\end{tabular}

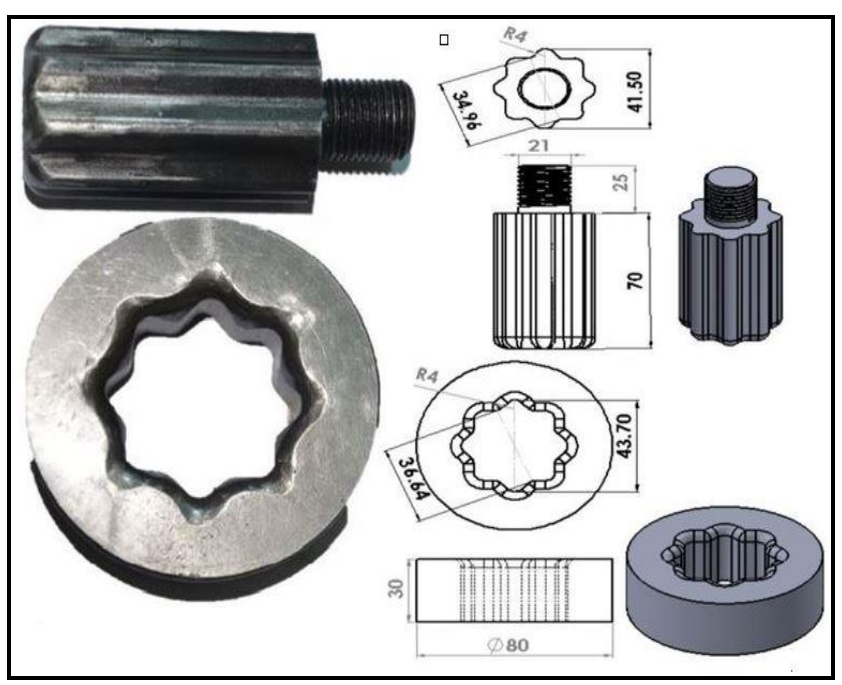

Fig. 4 Photograph shows the stellar punch and die used in the deep drawing process 


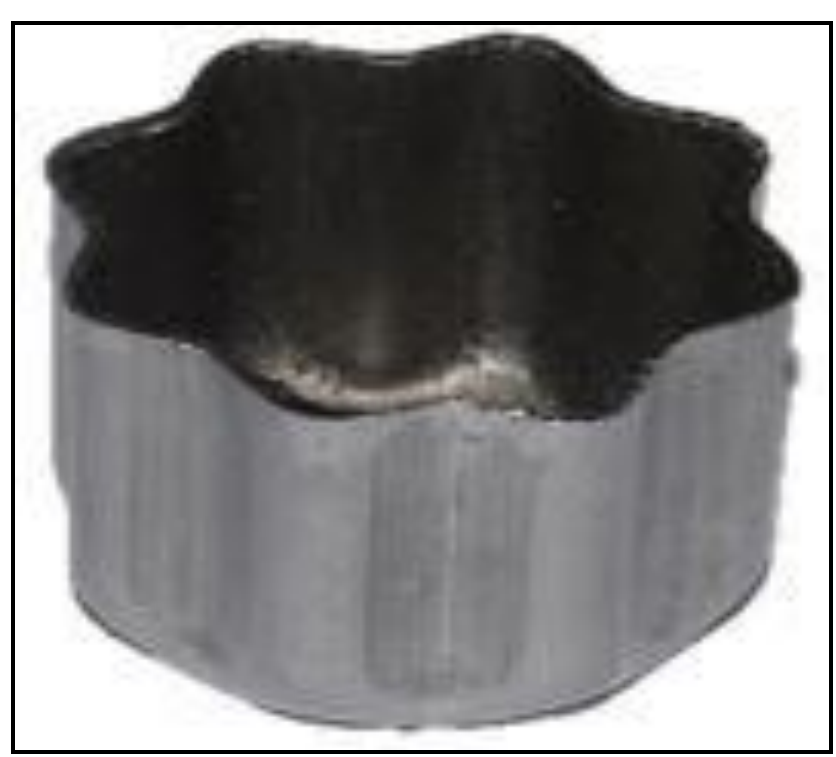

Fig. 5 Photograph indicates the staller cup produced.

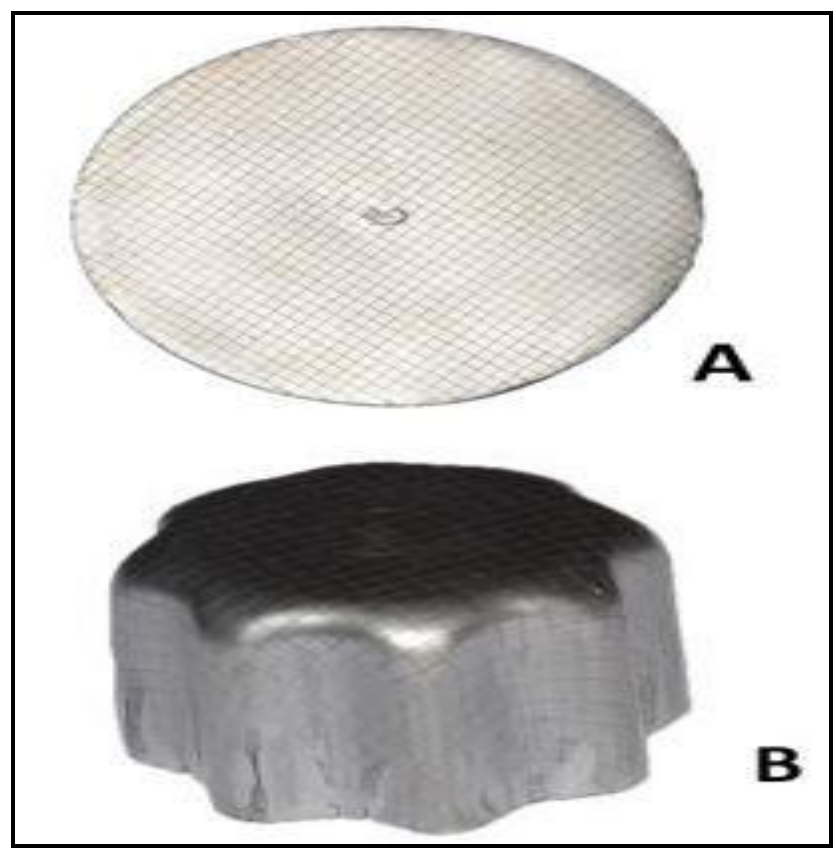

Fig. 6 Photograph shows, (A) unshaped sheet with grids, (B) deformed grids on the stellar cup.

\section{Results and discussion}

\subsection{Effect of wall corner radius of punch}

Figure (7) shows the drawing load difference with the punch stroke under the effect of the wall corner radius of punch in deep drawing operation. It is shown that the value of the drawing force for small wall corner radius of punch is higher than that for the large wall corner radius of punch, in both simulation and experimental work. This is due to the effect of bending intensity on small wall corner radius of punch compared to the little effect of bending on large wall corner radius of punch. It is clear from the figure, the drawing force for all values of wall corner radius of punch reaching the maximum value and started to drop.

Figure (8) represents the effect of the wall corner radius of the punch on the thickness distribution across the side wall, the corner of the major axis and the corner of the minor axis of completely drawn cup. It is clear from the figure at cup corner, the thinning occurs and increases with decreasing wall corner radius of punch. The maximum thinning occurs with the smallest value of the wall corner radius of the punch $\left(R_{c p}=2 \mathrm{~mm}\right)$ at the corner of minor axis as shown in the Figure (6-2C). Because of the highest concentration of stresses obtained with the wall corner radius of the punch $\left(R_{c p}=2 \mathrm{~mm}\right)$ resulting in the highest thinning. While at the cup rim, the maximum thickening occurs with the large value of wall corner radius of the punch $\left(R_{c p}=6 \mathrm{~mm}\right)$ at the corner of the major axis as shown in the Figure (6-2A). This is due to increased hoop stress in this area.

Figures (9-10) indicate the effect of the wall corner radius of the punch on the distribution of the effective strain and stress along the side wall, the corner of the major axis and the corner of the minor axis of completely the drawn cup. It is clear from this figures that the effective strain and stress distributions for all regions of drawn cup are similar in shape, and have the same trend. The maximum values of effective strain and stress with the smallest value of wall corner radius of the punch $\left(R_{c p}=2\right.$ $\mathrm{mm})$ at the corner of minor axis at cup rim as shown in the Figures (6-2C and 7-2C) respectively, this is due to excessive tension occurs at the corner of minor axis. Table (3) shows the maximum values for recorded results for practical tests and numerical simulators.

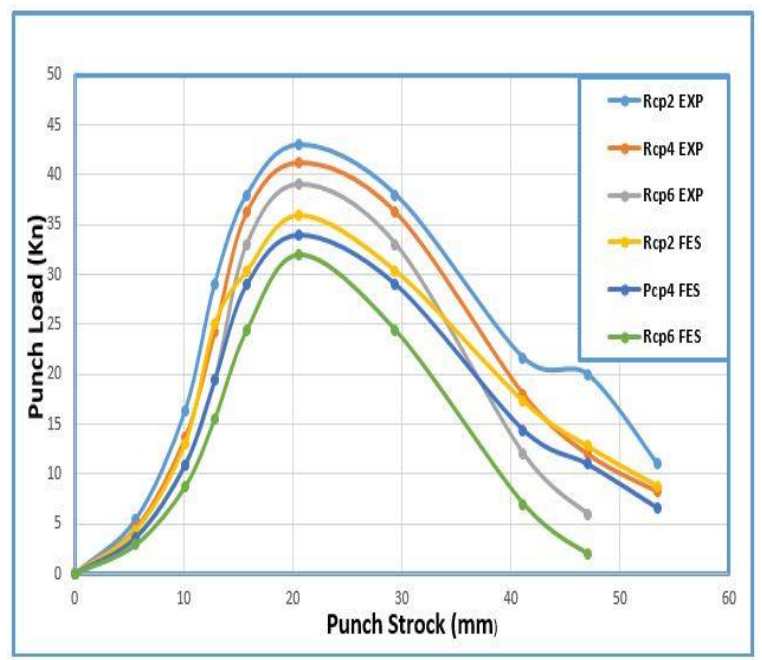

Fig. 7 Photograph shows the punch load under variance wall corner radius of punch. 


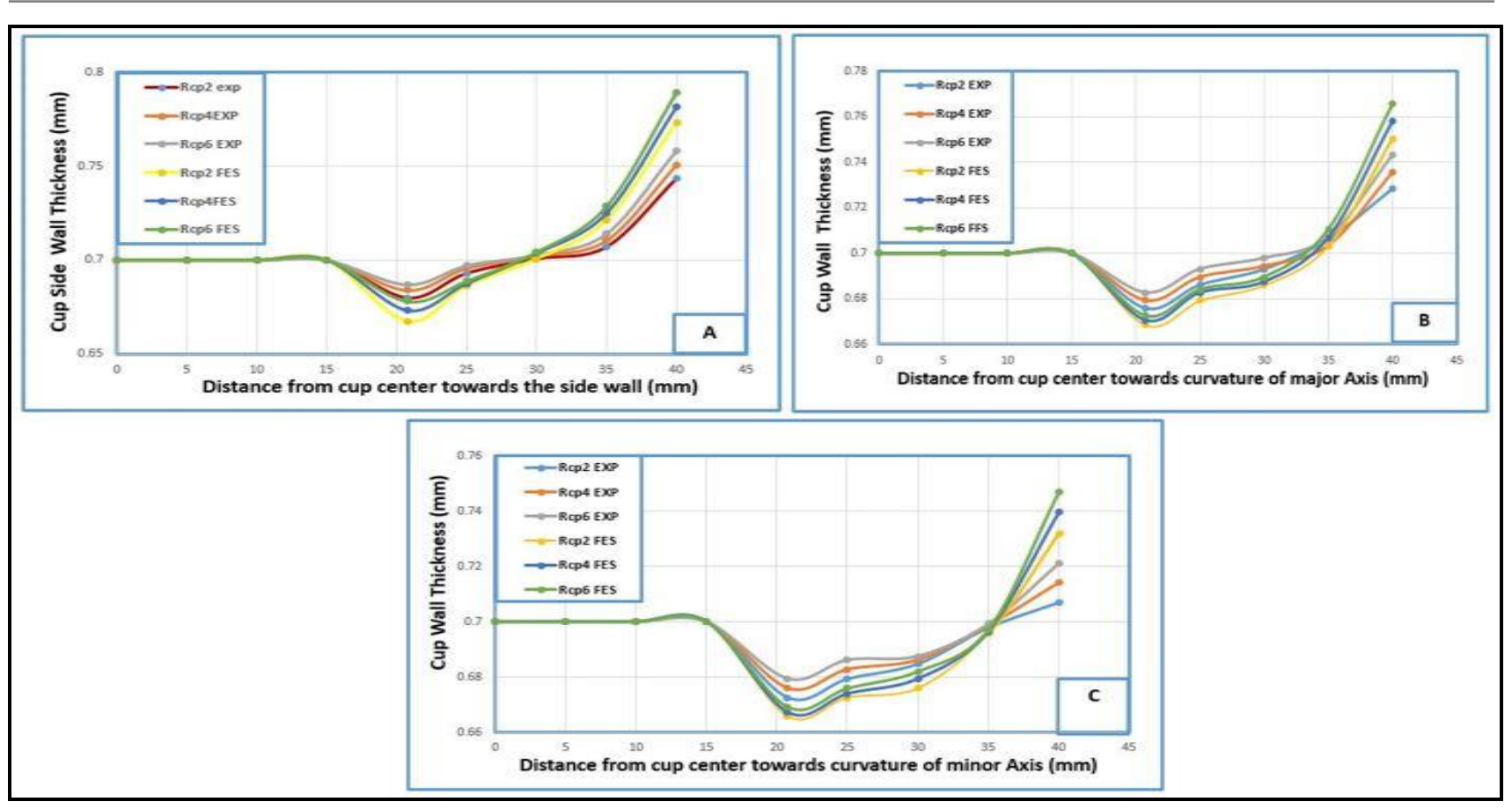

Fig. 8 Photograph shows the effect of wall corner radius of punch on thickness distribution.
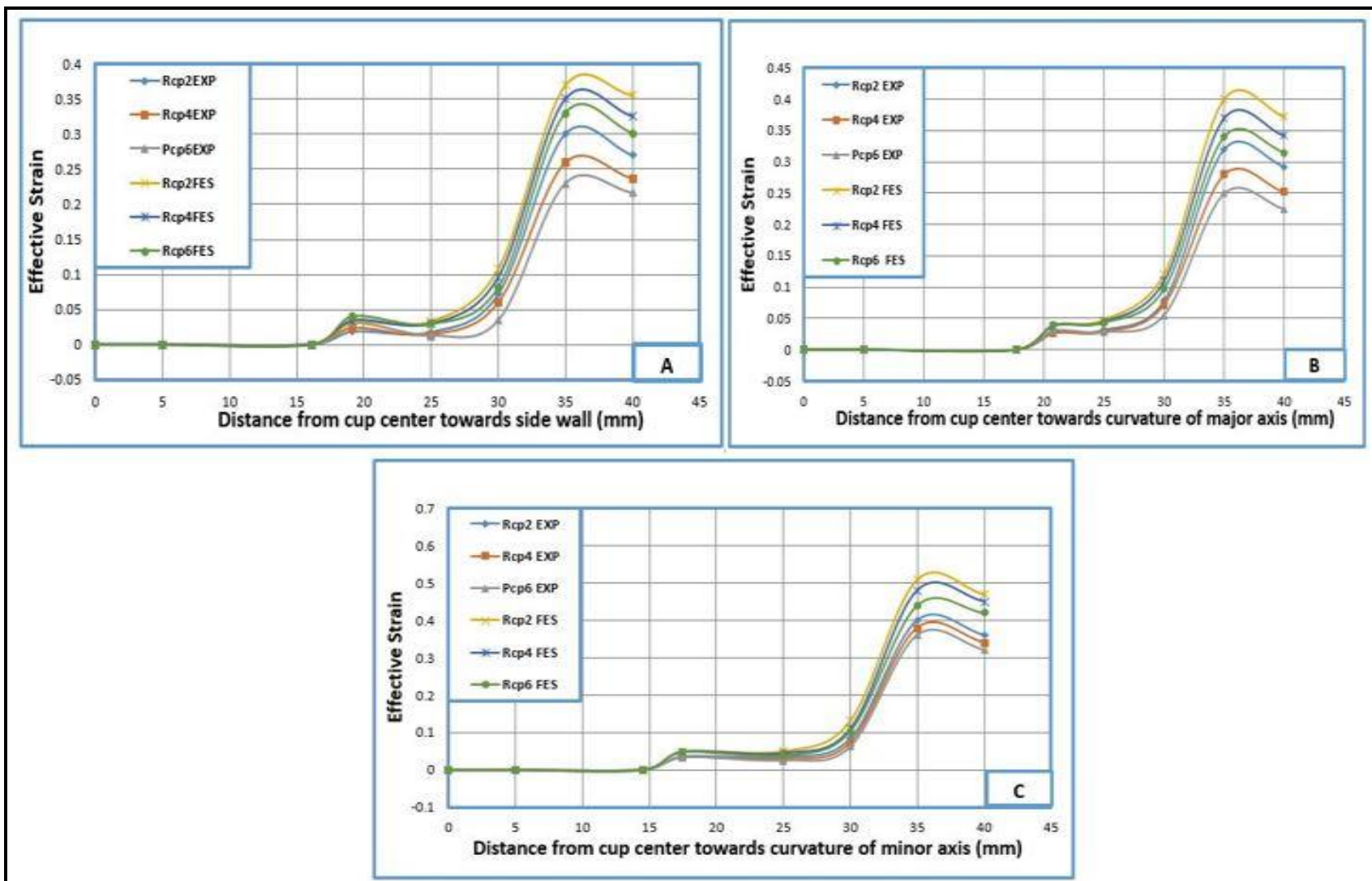

Fig. 9 Photograph shows the effect of wall corner radius of punch on strain distribution 


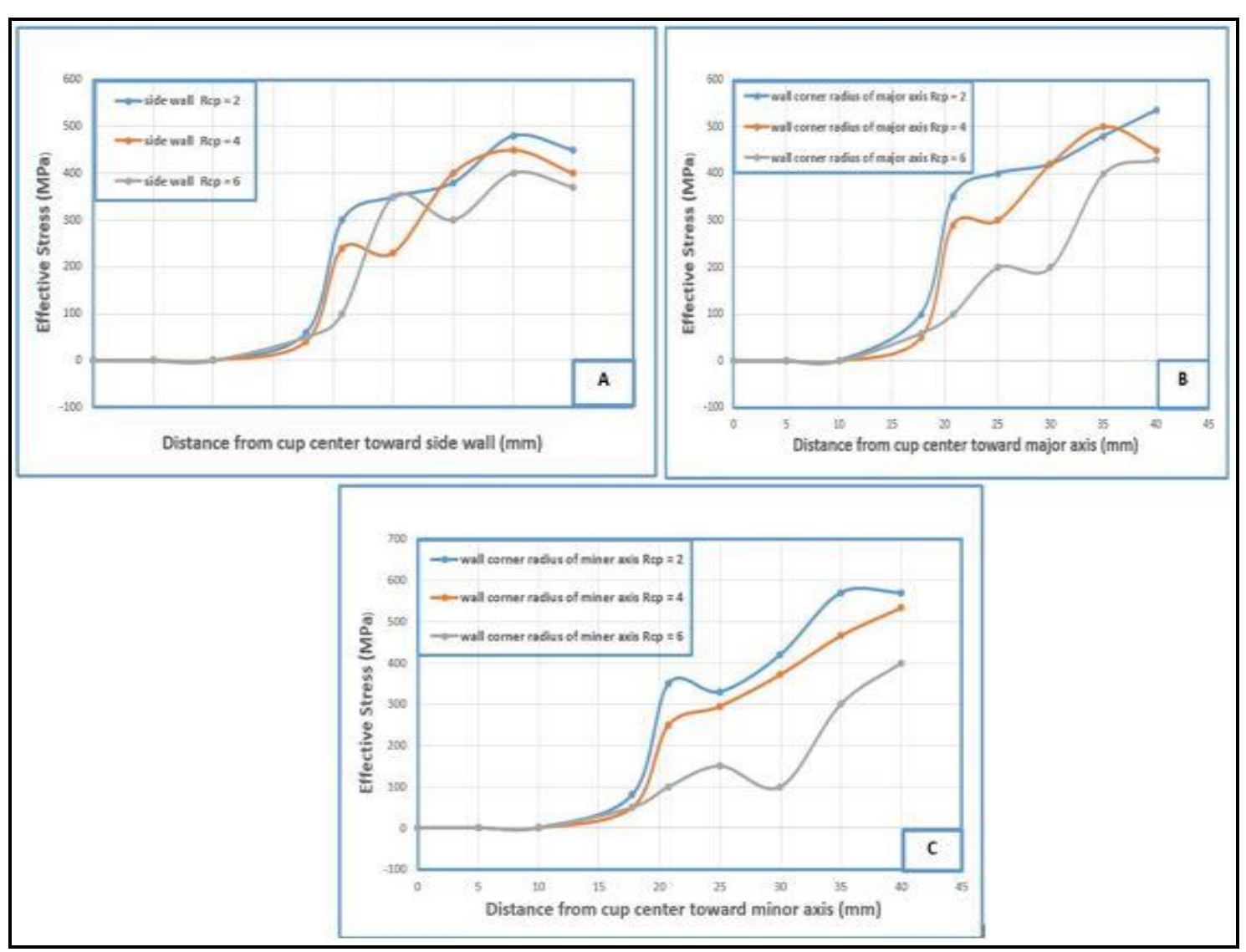

Fig. 10 Photograph shows the effect of wall corner radius of punch on stress distribution.

Table 3 The maximum values for recorded results for the practical tests and numerical simulation.

\begin{tabular}{|c|c|c|c|c|c|}
\hline $\begin{array}{c}R_{\text {cp }} \\
\mathrm{mm}\end{array}$ & \multicolumn{2}{|c|}{$\begin{array}{c}\text { Max drawing } \\
\text { Force (KN) }\end{array}$} & \multicolumn{2}{c|}{$\begin{array}{c}\text { Max effective } \\
\text { strain }\end{array}$} & \multicolumn{2}{|c|}{$\begin{array}{c}\text { Max } \\
\text { effective } \\
\text { Stress (MPa) }\end{array}$} \\
\hline & FES & EXP & FES & EXP & FES \\
\hline 2 & 43.21 & 36.31 & 0.4732 & 0.3781 & 570 \\
\hline 4 & 41.28 & 34.26 & 0.4522 & 0.3483 & 534 \\
\hline 6 & 39.34 & 32.26 & 0.4212 & 0.3211 & 400 \\
\hline
\end{tabular}

4.2 Effect of radial clearance on the distribution of thickness

Figure (11) represents the behavior of the distribution of thickness under the effect of radial clearance using numerical simulation. Four value of radial clearance (1.1 $\mathrm{t}_{\mathrm{o}}, 1.15 \mathrm{t}_{\mathrm{o}}, 1.2 \mathrm{t}_{\mathrm{o}}$ and $1.25 \mathrm{t}_{\mathrm{o}}$ ) are used. It is noted that from the figure, the smaller clearance, maximum thinning takes place at cup corner with clearance $\left(1.1 \mathrm{t}_{\mathrm{o}}\right)$ at the corner of the minor axis and a larger ironing effect occurs at the stellar cup and an irregular thickness is obtained. This effect increases the wear of the punch and the die. The greater clearance $\left(1.25 \mathrm{t}_{\mathrm{o}}\right)$, the cup thickness after the drawing is greater at the side wall, but the thickness will not be uniform and appears wrinkling appears on the wall of completely dawn cup. 


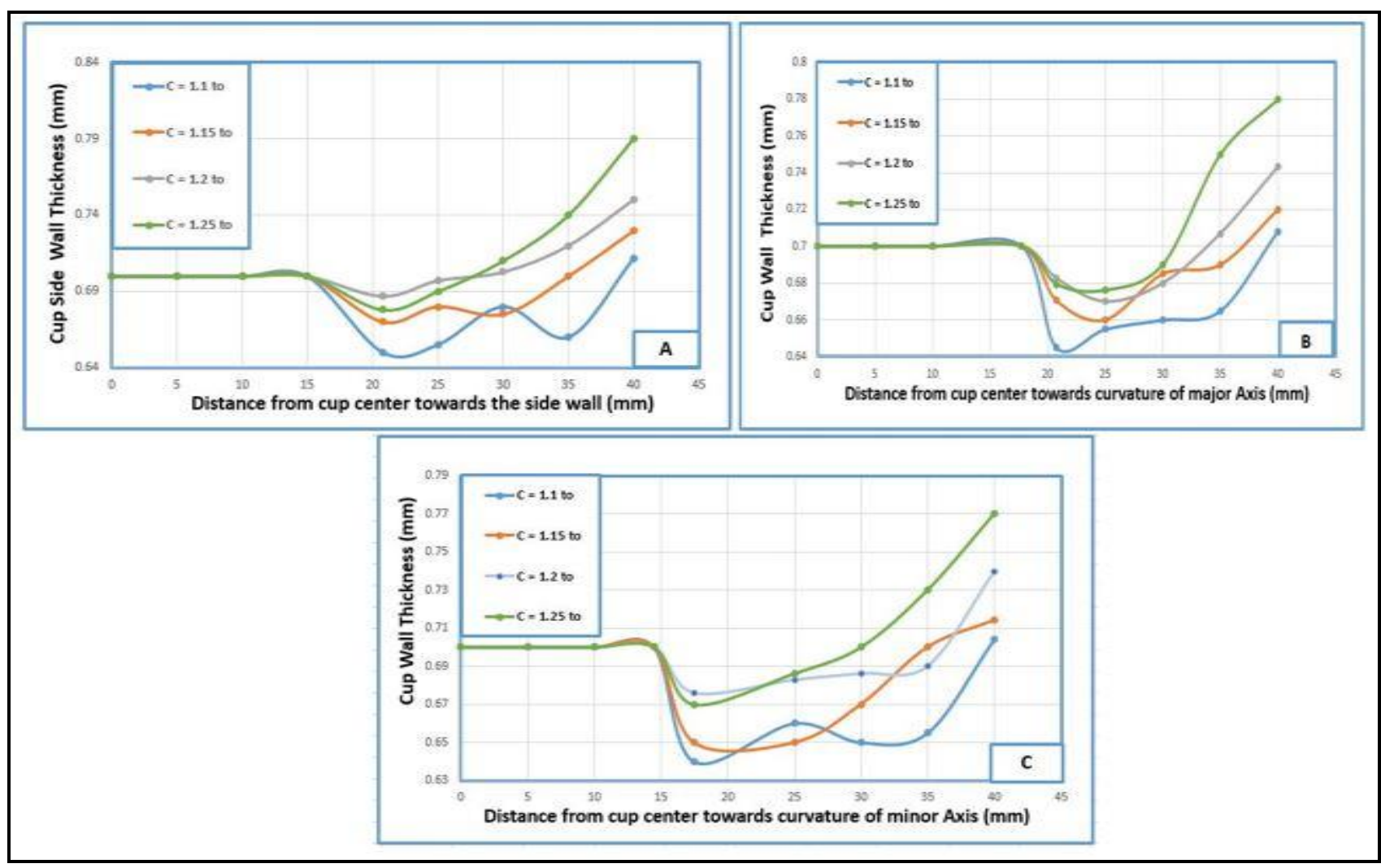

Fig. 11 Photograph shows the effect of radial clearance on stress distribution.

\section{Conclusion}

1. The drawing force for small wall corner radius of punch is lighter than that for large wall corner radius of punch.

2. The maximum thinning occurs with the smallest value of wall corner radius of the punch $\left(R_{c p}=2 \mathrm{~mm}\right)$ at the corner of minor axis while the maximum thickening occurs with the large value of wall corner radius of the punch $\left(R_{c p}=6 \mathrm{~mm}\right)$ at the side wall.

3. The maximum values of effective strain and stress with the smallest value of wall corner radius of the punch $\left(R_{c p}=2 \mathrm{~mm}\right)$ at the corner of minor axis at cup rim.

4. The maximum thinning takes place at cup the corner with clearance $\left(1.1 \mathrm{t}_{\mathrm{o}}\right)$ at corner of the minor axis.

5. The minor axis and a larger ironing effect occurs at the stellar cup and uniform thickness is obtained.

6. The greater clearance $\left(1.25 \mathrm{t}_{\mathrm{o}}\right)$, the cup thickness after the drawing is greater at the side wall, but the thickness will not be uniform and the wrinkling appears on the wall of completely dawn cup.

7. The best design for the drawing die can produce products with no defects when using the wall corner radius of punch equal to $\left(R_{c p}=4\right)$ and radial clearance equal to $\left(1.2 \mathrm{t}_{\mathrm{o}}\right)$.

8. The clearance value of the stellar shape $((1.2$ $\left.t_{0}\right)$ ) gives the best product without defects when compared with other shapes such as the cylindrical, rectangle, square and conical, which takes the value of clearance $\left(1.1 \mathrm{t}_{\mathrm{o}}\right)$ to give a product without defects.

9. A comparison between theoretical (simulation) and experimental results lie within an average of $(13-23 \%)$.

\section{References}

[1] A. H. Saleh, and A. K. Ali, "Development technique for deep drawing without blank holder to produce circular cup of brass alloy ", International Journal of Engineering \& Technology, 2015, 4, 1, 187.

[2] S. S. Han and H. Huh, "Modified-membrane finiteelement simulation of square cup drawing processes 
considering influence of geometric parameters die", Journal of Materials Processing Technology, 1995, 48,

81.

[3] S. Anwekar and A. Jain, "Finite Element Simulation of Single Stage Deep Drawing Process for Determining Stress Distribution in Drawn Conical Component", International Journal of Computational Engineering Research, 2012, 2, 229.

[4] A C. Reddy, S. Rajesham and P. R. Reddy, "Experimental study on strain variation and thickness distribution in deep drawing of axisymmetric components", International Journal of Engineering Research \& Technology, 2013, 2, 2214.

[5] P. Alin, M. Ioan and R. Ioan, "Parameters influence on wrinkling in deep drawing cylindrical cups", Romanian Association of Nonconventional Technologies, 2013, 76, 59.

[6] B. Sener1, and H. Kurtaran, "modeling the deep drawing of an AISI 304 stainless-steel rectangular cup using the finite-element method and an experimental validation", Materials and technology, 2016, 50, 6, 961.

[7] U Pranavi, P. J. Ramulu and C. Chandramouli, "Formability analysis of aluminum alloys through deep drawing process", Materials Science and Engineering, 2016, 149, 1 .

[8] K. M. Younis, A. S. Jabber and M. M. Abdulrazaq, "Experimental evaluation and finite element simulation roduce square cup by deep drawing process", $\mathrm{Al}$ Khwarizmi Engineering Journal, 2018, 43, 1, 39. 